\title{
Energy Conservation in Air Supply Unit Used for Ventilation Purpose in Automobile Industries
}

\author{
Prakash B. Salunkhe ${ }^{1}$, P. P. Mahajan ${ }^{2}$ \\ ${ }^{1}$ PG. Student, Department of Electrical Engineering, AISSMS Institute of Information Technology, Pune, Maharashtra, India \\ ${ }^{2}$ Assistant Professor, Department of Electrical Engineering, AISSMS Institute of Information Technology, Pune, Maharashtra, India
}

\begin{abstract}
In the application of Air Supply Unit (ASU) high power rating three phase induction motor is used. The electric drive systems used in industrial applications are increasingly required to meet the higher performance and reliability. Today about $90 \%$ of all industrial motor applications use three phase induction motors because they are simple in design, easy to maintain, and are less costly than other designs. The traditional method of such flow control of ASU is use an induction motor run at constant speed with 50-Hz power supply and then control the flow by means of a throttle. As per the fan affinity law where the load torque and power vary with the square and cube, respectively of the speed. If reducing RPM by $10 \%$ decrease the power requirement by $27 \%$. This change gives a large power reduction compared to fixed-speed operation. Relatively small reduction in speed gives large saving in energy consumption. Also by Using a variable frequency drive to control the air flow with a fully open throttle saves a considerable amount of power. The ASU does not need to be run at full speed throughout the day and therefore, a variable frequency drive can be employed to reduce the ASU motor speed. The main aim of this paper is to reduce the energy consumption by the implementation of VFD. Hence the proper control of air flows is achieved and increases the motor life. For the flow control with energy saving in centrifugal fan we propose to use variable speed drive.
\end{abstract}

Keywords: Air supply unit, Centrifugal fan, Variable frequency drive, Fans law

\section{Introduction}

Air Supply Unit (ASU) is equipment used in industry to circulate, supply or replace air. ASU is commonly known as Air Replacement Plant, Air Handling Unit, and Air Makeup Unit etc. ASU was very popular in areas where the air has low humidity, and hotter climate. Mainly ASU is required to comfort the human conditions in such climate. As technology has changed for better development, even in the field of paint and painting equipments, more and more expansions have added up to make a dust free painted product .To attain such a clean paint film on the product free from dust above 5 micron, ASU have become a necessity of today's market.

ASU uses the atmospheric air from outside, refines the air, and supplies it via ducting, thus creating a constant flow of dust free air. The volume of air supplied from the ASU also helps to maintain a positive pressure in the shop, thus not allowing external dust. ASU creates an enclosed environment safer for workers by facilitating the elimination of toxic

fumes.

ASU are not only used to provide make up air for the paint booth, but also used as a spot cooling device for the workers in molding and welding shops, assembly shops and other otter areas. Basically welding operation is carryon in weld shop, it produces lot of heat. Therefore atmospheric temperature is high, to reduce this temperature fresh ASU is required. As per area and temperature required ASU is installed at various locations.

ASU is nothing but a centrifugal fan driven by high power three phase induction motor. Fans generate a pressure to move air against a resistance caused by ducts, dampers, or other components in a fan system. The fan rotor receives energy from a rotating shaft and transmits it to the air.

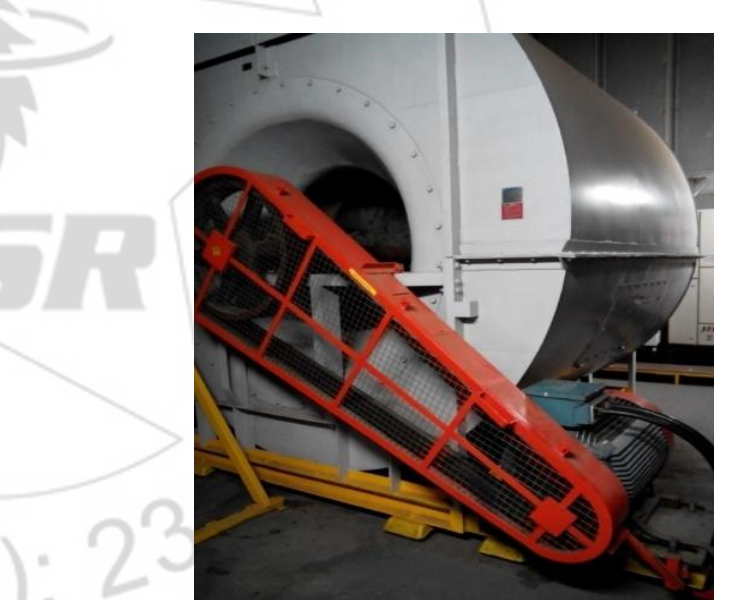

Figure 1: Centrifugal Fan and Motor

\section{Working of ASU}

ASU has three sections filter, motor and water spray section (see Fig-2). Inlet air is taking from atmosphere in filter section, it filtered air. These clean airs is suck by centrifugal fan and through in the water spray section with pressure. After this clean air is passed though water cooled cellular pad. This clean and cool air is dispatch to workstation through duct. 


\section{International Journal of Science and Research (IJSR) \\ ISSN (Online): 2319-7064}

Index Copernicus Value (2013): 6.14 | Impact Factor (2015): 6.391

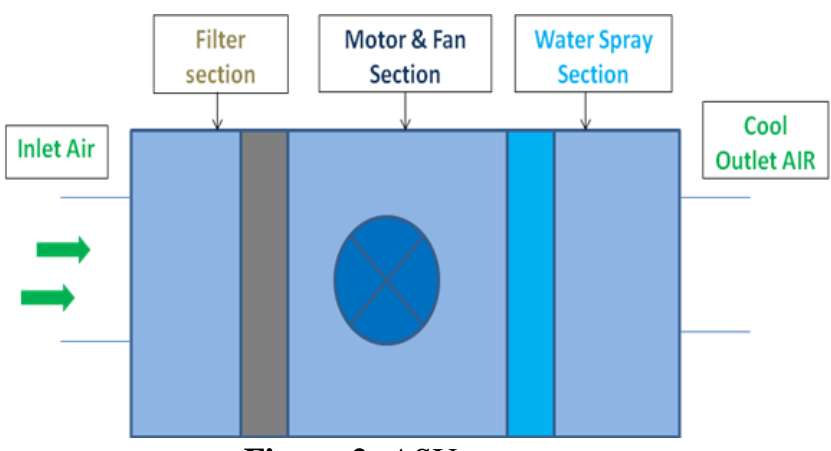

Figure 2: ASU structure

\section{Literature Review}

Fans and blowers provide air for ventilation and industrial process requirements. Fans generate a pressure to move air against a resistance caused by ducts, dampers, or other components in a fan system. The fan rotor receives energy from a rotating shaft and transmits it to the air.

\subsection{Fan Types}

Fans fall into two general categories: centrifugal flow and axial flow.

- In centrifugal flow, airflow changes direction twice - once when entering and second when leaving (forward curved, backward curved or inclined, radial).

- In axial flow, air enters and leaves the fan with no change in direction (propeller, tube axial, vane axial).

\subsection{Fan Laws}

The fans operate under a predictable set of laws concerning speed, power and pressure. A change in speed (RPM) of any fan will predictably change the pressure rise and power necessary to operate it at the new RPM.
a) flow $\propto$ Speed
c)power $\propto(\text { speed })^{a}$
b) pressure $\propto$ (speed $)^{2}$,

As per the law small reduction in speed, power requirement is highly reduced. Normally if speed is reduced by $10 \%$ decreases $27 \%$ power requirement \& decrease $19 \%$ static pressure.

\section{Flow Control Strategies}

Typically, once a fan system is designed and installed, the fan operates at a constant speed. There may be occasions when a speed change is desirable, i.e., when adding a new run of duct that requires an increase in air flow (volume) through the fan. There are also instances when the fan is oversized and flow reductions are required. Traditionally ways to achieve change in flow are: pulley change, damper control, inlet guide vane control. Normally today in all industry damper control method is used. Variable speed drive is most beneficial method for flow control and high energy conservation.

\subsection{Pulley Change}

The air volume change can be achieved with a speed change. The simplest way to change the speed is with a pulley change. For this, the fan must be driven by a motor through a v-belt system. The fan speed can be increased or decreased with a change in the drive pulley or the driven pulley or in some cases both pulleys.

\subsection{Damper control}

Some fans are designed with damper controls (see Fig-3). Dampers can be located at inlet or outlet. Dampers provide a means of changing air volume by adding or removing system resistance. This resistance forces the fan to move up or down along its characteristic curve, generating more or less air without changing fan speed.

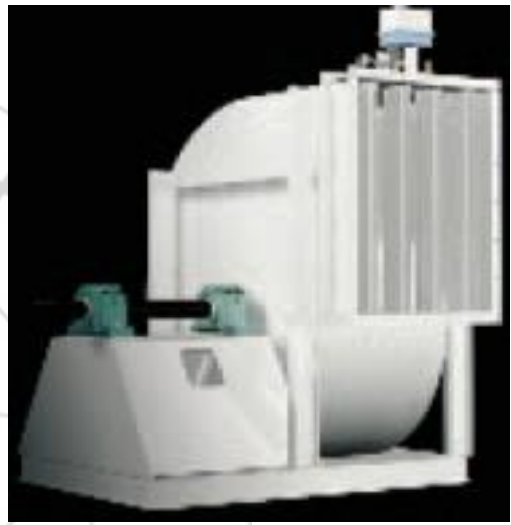

Figure 3: Damper control

\subsection{Inlet Guide Vanes}

Inlet guide vanes are another mechanism that can be used to meet variable air demand (see Fig-4). Guide vanes are curved sections that lay against the inlet of the fan when they are open. When they are closed, they extend out into the air stream. As they are closed, guide vanes pre-swirl the air entering the fan housing. This changes the angle at which the air is presented to the fan blades, which, in turn, changes the characteristics of the fan curve. Guide vanes are energy efficient for modest flow reductions - from 100 percent flow to about 80 percent. Below 80 percent flow, energy efficiency drops sharply.

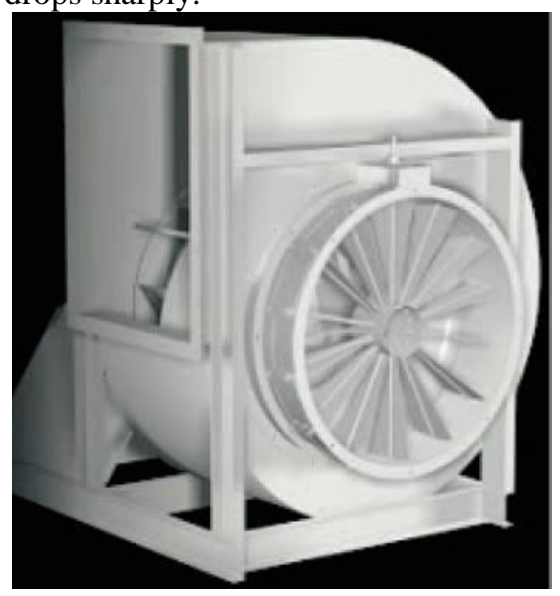

Figure4: Inlet guide Vane 


\section{International Journal of Science and Research (IJSR) \\ ISSN (Online): 2319-7064}

Index Copernicus Value (2013): 6.14 | Impact Factor (2015): 6.391

\subsection{Variable Speed Drives}

Although, variable speed drives are expensive, they provide almost infinite variability in speed control. Variable speed operation involves reducing the speed of the fan to meet reduced flow requirements. Fan performance can be

predicted at different speeds using the fan laws. Since power input to the fan changes as the cube of the flow, this will usually be the most efficient form of capacity control.

\section{Comparison between Different Method}

Table 1: Comparison between different methods

\begin{tabular}{|c|c|c|c|}
\hline Pulley Change & Damper Control & Inlet guide Vanes & Variable Speed Drive \\
\hline $\begin{array}{l}\text { Drawbacks: } \\
\text { 1. Change is permanent. } \\
\text { 2. It changes capacity. } \\
\text { 3. Mechanical losses increase. }\end{array}$ & $\begin{array}{l}\text { Drawbacks: } \\
\text { 1. Speed not change. } \\
\text { 2.Resistance increases } \\
\text { 3.Limited adjustment } \\
\text { 4. No Energy efficient. } \\
\text { 5. Forces characteristic } \\
\text { up or down. }\end{array}$ & $\begin{array}{l}\text { Drawbacks: } \\
\text { 1. Below } 80 \% \text { flow, energy efficiency } \\
\text { drops sharply. } \\
\text { 2. Required variable pitch blades. } \\
\text { 3. Hydraulic or pneumatic controlled to } \\
\text { change blade pitch. } \\
\text { 4. Limited adjustment. }\end{array}$ & $\begin{array}{l}\text { Drawbacks: } \\
\text { 1. High cost. } \\
\text { 2. Maintenance cost high. } \\
\end{array}$ \\
\hline $\begin{array}{l}\text { Benefit: } \\
\text { 1. Simple method. } \\
\text { 2. Low cost. }\end{array}$ & $\begin{array}{l}\text { Benefit: } \\
\text { 1. Simple method. } \\
\text { 2. Low cost. }\end{array}$ & $\begin{array}{l}\text { Benefit: } \\
\text { 1. Simple method. }\end{array}$ & $\begin{array}{l}\text { Benefit: } \\
\text { 1. Provides infinite variability in speed. } \\
\text { 2. Meet reduced flow of air as required. } \\
\text { 3. Highly energy efficient. } \\
\text { 4. Performance can be predicted. }\end{array}$ \\
\hline
\end{tabular}

Fig-5 shows the power requirement for different flow control methods. Power requirement for VFD method is very less than other methods. So VFD method is proposed for flow control with considerable energy conservation in ASU.

\section{Motivation}

There has been an enormous increase in the global demand for energy in recent years as a result of industrial development and population growth. Since, our conventional sources of energy or fossil fuels are running short; it is now the cry of the day to work harder for the development, improvement and up gradation of renewable sources of energy with protection, conservation and existing conventional sources. The reduction in the amount of energy consumed in a process or system, or by an organization or society through economy and elimination of wastage is called as energy conservation.

\section{Problem Definition}

In the existing ASU system motor is run direct from star delta starter. No any seed control method is used. Fan run at full speed at all the time in all whether condition. In winter season air pressure requirement is very less but in existing system no provision for control the speed of motor. Hence unnecessary fan run at full speed and energy wasted.

Figure 5: Power requirement vs. rated fan volume at all method
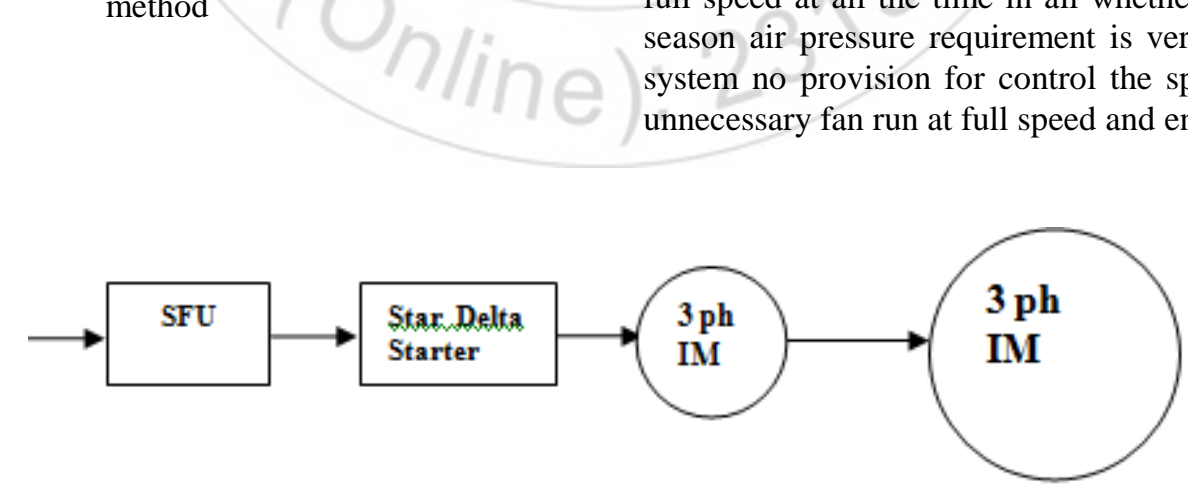

Figure 5: Existing ASU system

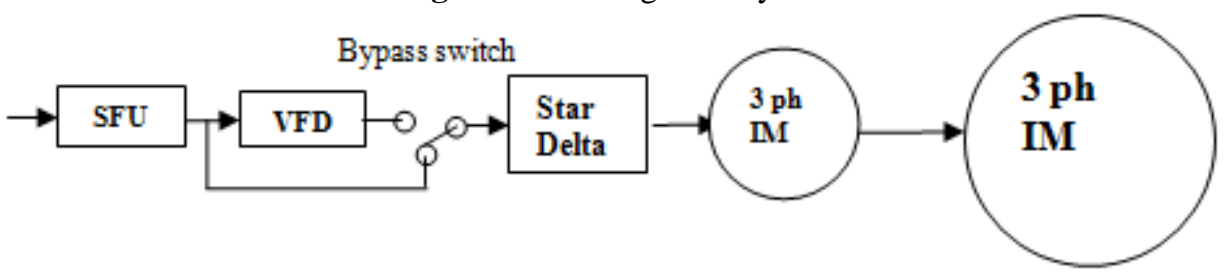

Figure 6: Proposed ASU system 


\section{International Journal of Science and Research (IJSR) \\ ISSN (Online): 2319-7064}

Index Copernicus Value (2013): 6.14 | Impact Factor (2015): 6.391

So propose to install VFD in series with motor. Requirement of bypass switch is for bypass the VFD in under breakdown condition.

\section{Scope of Work}

Motor Rating of ASU: ABB make, 3 ph Squirrel Cage Induction Motor, $125 \mathrm{HP}, 90 \mathrm{Kw}, 1475$ Rpm, 157 Amp, 415 $\mathrm{V}$. As per fans law (power $\propto$ (speed) ${ }^{\mathrm{a}}$ ) power required for different speed can calculated.

Power is proportional to the cube of the shaft speed;

$\frac{P_{1}}{P_{2}}=\left(\frac{N_{1}}{N_{2}}\right)^{3}$

Where $\mathrm{kW}=$ Power, $\mathrm{N}=$ Speed in $\mathrm{rpm}$

Reading of ASU motor at $50 \mathrm{~Hz}$ frequency:

Table 2: Reading of ASU at normal load

\begin{tabular}{|c|c|c|c|c|c|}
\hline $\mathrm{V}_{\mathrm{ph}}$ & $\mathrm{V}_{\mathrm{L}}$ & $\mathrm{I}_{\mathrm{L}}$ & Power & Freq. & Speed \\
\hline $\mathrm{V}$ & $\mathrm{V}$ & $\mathrm{A}$ & $\mathrm{kW}$ & $\mathrm{Hz}$ & $\mathrm{Rpm}$ \\
\hline 239 & 416 & 107 & 63 & 50 & 1490 \\
\hline
\end{tabular}

Find the slip of motor,

$\mathrm{Ns}=\frac{120 \mathrm{f}}{\mathrm{p}}=\frac{120 \times 50}{4}=1500 \mathrm{rpm}$

$\mathrm{Sl}=\frac{\mathrm{Ns}-\mathrm{Nr}}{\mathrm{Ns}}=\frac{1500-1490}{1500} \times 100=0.66 \%$

If frequency is reduced $45 \mathrm{~Hz}$,

So,

$\mathrm{Ns}=$ Synchronous speed $=\frac{120 \mathrm{f}}{\mathrm{p}}=\frac{120 \times 45}{4}=1350 \mathrm{rpm}$

Assume slip is constant $0.66 \%=0.006$

Find $\mathrm{Nr}$ at $45 \mathrm{~Hz}$ freq.

$\mathrm{Nr}=\mathrm{Ns}-(\mathrm{Sl} \times \mathrm{Ns})=1350-(0.006 \times 1350)=1341 \mathrm{rpm}$

As per fans law,kW1=63, N1=1490, N2=1341,

find $\mathrm{kW} 2=$ ?

$\mathrm{kW} 2=\frac{\mathrm{kW} 1 \times\left(\mathrm{N} 2^{\mathrm{a}}\right)}{\left(\mathrm{N} 1^{\mathrm{a}}\right)}=\frac{63 \times 1341^{\mathrm{a}}}{1500^{\mathrm{a}}}=45.01 \mathrm{~kW}$

Power requirement is $45 \mathrm{~kW}$ at $45 \mathrm{~Hz}$ freq.

Reduction in power requirement $=63-45.01=17.98 \mathrm{~kW}$

As pre above example calculated energy saving for different frequency \& speed below.

Table 3: Power requirement at different speed

\begin{tabular}{|c|c|c|c|c|c|}
\hline $\begin{array}{c}\text { Sr. } \\
\text { No. }\end{array}$ & $\begin{array}{c}\text { Freq. } \\
(\mathrm{Hz})\end{array}$ & $\begin{array}{c}\mathrm{Ns} \\
(\mathrm{rpm})\end{array}$ & $\begin{array}{c}\mathrm{Nr} \\
(\mathrm{rpm})\end{array}$ & $\begin{array}{c}\text { Required } \\
\text { Power }(\mathrm{kW})\end{array}$ & $\begin{array}{c}\text { Save power } \\
(\mathrm{kW})\end{array}$ \\
\hline 1 & 50 & 1500 & 1490 & 63 & 0 \\
\hline 2 & 45 & 1350 & 1341 & 45.01 & 17.98 \\
\hline 3 & 40 & 1200 & 1192 & 32.25 & 30.75 \\
\hline 4 & 35 & 1050 & 1043 & 21.6 & 41.4 \\
\hline 5 & 30 & 900 & 894 & 13.6 & 49.4 \\
\hline 6 & 25 & 750 & 745 & 7.875 & 55.125 \\
\hline 7 & 20 & 600 & 596 & 4.032 & 58.968 \\
\hline
\end{tabular}

\section{Conclusions}

In this paper it is found that, the speed control of induction motor using VFD can save energy according to fans (affinity) law. According to this assumption a small reduction in speed can save a large amount of energy. Apart from speed control and energy savings, the uses of VFD provide soft start, reduction in starting current, reduce tear and wear and increases the life of motor. This method gives infinite variability in speed and performance of the ASU can be predicted.

\section{References}

[1] Neetha John, Mohandas R, Suja C Rajappan,' Energy Saving Mechanism Using Variable Frequency Drives", International Journal of Emerging Technology and Advanced Engineering Volume 3, Issue 3, March 2013.

[2] Handbook on 'Energy Audits and Management ',Tata Energy Res. Inst (TERI) New Delhi 2000.

[3] B. K. Bose, Ed.," Power Electronics and Variable Frequency Drives' '.New York: IEEE Press, 1996.

[4] M. Deepa "Design of VFD Drive for a 3-Phase Induction Motor" International Journal of Innovative Research in Science, Engineering and Technology Vol. 4, Issue 1, January 2015.

[5] W. Leonhard, "Control of electrical drives", 2-nd Ed, Springer, 1996.

[6] 'VFD Fundamentals" Copyright 2003 Kilowatt Classroom, LLC.

\section{Author Profile}

Prakash B. Salunkhe is working as an maintenance team member in Tata Motors, PVBU Pune. He has obtained B.E. (Electrical) from Pune University, India in 2013. He is P.G. student (Power electronics and Drive) in AISSMS Institute of Information Technology, Pune.

P.P. Mahajan is working as an Assistant Professor, Department of Electrical Engineering, AISSMS Institute of Information Technology, Pune. 